Check for updates

Cite this: RSC Adv., 2017, 7, 31244

\title{
Promoting lentil germination and stem growth by plasma activated tap water, demineralized water and liquid fertilizer
}

\begin{abstract}
S. Zhang, A. Rousseau and T. Dufour (iD *
Tap water, demineralized water and liquid fertilizer have been activated using an atmospheric pressure plasma jet (APPJ) to investigate their benefits for the germination rate and stem elongation rate of lentils from Puy-en-Velay (France). By plasma-activating tap water, we have obtained germination rates as high as $80 \%$ (instead of $30 \%$ with tap water). Also, higher stem elongation rates and final stem lengths were obtained using activated tap water compared with commercial fertilizer. We show that these rates of germination and stem growth strongly depend on the combination of two radicals generated in the liquids by the plasma: hydrogen peroxide and nitrate. This synergy appears to be a condition for releasing seed dormancy through the endogenous production of NO radicals.
\end{abstract}

Received 25th April 2017

Accepted 3rd June 2017

DOI: $10.1039 / \mathrm{c} 7 \mathrm{ra04663d}$

rsc.li/rsc-advances

reports have indicated that this type of plasma treatment could enhance or modify the germination and/or growth of oilseed rape seeds ${ }^{13}$ bean and wheat seeds. ${ }^{14-16}$ Direct plasma treatments of tomato, radish and mulungu also gave positive effects. ${ }^{17-20}$ On the other hand, plasma activated liquids (PALs) (mainly different types of water) provide a much greater degree of mobility for CAP used in agriculture and could be much more convenient in the industry. So far, few studies have reported plasma processes dedicated to the activation of liquids for agricultural applications; however, researchers have recently developed a process to improve germination rates of radishes, tomatoes and sweet peppers. ${ }^{21-23}$ Hence, they obtained an increase as high as $80 \%$ in the germination rate in the case of radishes while stem elongation of $60 \%$ was obtained for tomatoes.

In this work, tap water, demineralized water and liquid fertilizer are used to irrigate seeds and seedlings from germination to early stage growth. These liquids are also exposed to an APPJ to obtain PALs. Since tap/demineralized waters have already shown differences for plant growth, ${ }^{24}$ we investigate here how these PALs can have important impacts on germination rates as well as on stem elongation. Two main radicals in the liquid phase are characterized: nitrates and hydrogen peroxide. Their respective effects on the agronomical parameters are discussed.

\section{Experimental setup}

The plasma source utilized for liquid activation is an APPJ as shown in Fig. 1. The APPJ is composed of a quartz dielectric tube (inner diameter $=4.5 \mathrm{~mm}$, outer diameter $=8 \mathrm{~mm}$ ) with an inner rod electrode (AC high voltage) and an annular grounded electrode. The AC high voltage is delivered by 


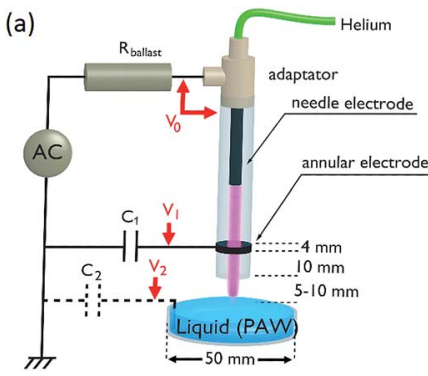

(b)

Fig. 1 (a) Schematic representation of the APPJ dedicated to the activation of liquids (b) schematic representation of the artificial lighting for six test tubes, each one containing 20 seeds and allocated to a specific experimental group.

a function generator (ELC Annecy France, GF467AF) and is amplified by a power amplifier (Crest Audio, $5500 \mathrm{~W}$, CC5500). A ballast resistor $(250 \mathrm{k} \Omega, 600 \mathrm{~W})$ protects the power supply from excessive currents that may result from plasma glow-to-arc transitions. A capacitor $(10 \mathrm{nF})$ is connected to the grounded electrode to monitor the plasma current. The APPJ is supplied with $500 \mathrm{sccm}$ helium controlled by a flow controller (MKS, model 1259C-00500SV). A glass vessel is placed 5-10 $\mathrm{mm}$ down from the APPJ to collect liquids with typical volumes of 10-20 $\mathrm{mL}$. After activation, the liquids are immediately poured onto the seeds or seedlings.

As reported in Table 1, six experimental conditions are considered (three PALs and their respective controls), each one corresponding to a test tube containing 20 seeds (lentils from Puy-en-Velay, France). The chemical composition of tap water is reported in Table 2. It was evaluated from 63 samples by the Agence Régionale de Santé (Ile-de-France region) on public networks and interior building networks from the $5^{\text {th }}$ district of Paris city, in February $2017 .{ }^{25}$ It is important to notice firstly the presence of nitrates $\left(30.7 \mathrm{mg} \mathrm{L}^{-1}\right)$ and secondly that the level of micro-organisms such as Enterococcus and Escherichia coli can be considered as negligible. The liquid fertilizer is a universal product commercialized by Truffaut@, dedicated to indoor plants and utilized following the supplier recommendations (dilution to $0.5 \%$ ). The fertilizer brings the essential elements (nitrogen, phosphorus, potash) to the soil to feed seedling roots. The micro-organisms in the soil transform these elements into mineral salts, which can then be assimilated by the seedlings to constitute their nutritional intakes.

The seeds are irrigated daily with controlled liquid volumes as follows: (i) on days 1 and 2,10 $\mathrm{mL}$ per day is poured into each test tube (and removed on the following day) so that all the

Table 1 The six experimental conditions investigated

\begin{tabular}{lll}
\hline Tube no. & Acronym & Description \\
\hline 1 & TAP Ctrl & Tap water control \\
2 & TAP PAL & Tap water plasma activated liquid \\
3 & DEM Ctrl & Demineralized water control \\
4 & DEM PAL & Demineralized water plasma activated liquid \\
5 & FTZ Ctrl & Liquid fertilizer control \\
6 & FTZ PAL & Liquid fertilizer plasma activated liquid
\end{tabular}

Table 2 Biochemical analysis of tap water from public networks and interior building networks measured in the $5^{\text {th }}$ district of Paris (Feb. 2017) by the Agence Régionale de Santé25

\begin{tabular}{|c|c|c|c|c|c|}
\hline Parameter & Unit & Min & Mean & $\operatorname{Max}$ & $\begin{array}{l}\text { Ref. limit } \\
\text { of quality }\end{array}$ \\
\hline $\mathrm{pH}$ & $\mathrm{pH}$ & 7.3 & 7.7 & 8.1 & $6.5-9$ \\
\hline Turbidity & NFU & 0.0 & 0.1 & 0.5 & 2 \\
\hline Free chlorine & $\mathrm{mg} / \mathrm{LCI} 2$ & 0.1 & 0.2 & 0.3 & - \\
\hline Nitrates & $\mathrm{mg} \mathrm{L}^{-1}$ & 23.6 & 30.7 & 37.4 & 50 \\
\hline Conductivity & $\mu \mathrm{S} \mathrm{cm}-1$ & 520.0 & 571.9 & 637.0 & 200-1100 \\
\hline Ammonia & $\mathrm{mg} \mathrm{L}^{-1}$ & 0.0 & 0.0 & 0.0 & 0.1 \\
\hline Escherichia coli & $n / 100 \mathrm{~mL}$ & 0.0 & 0.0 & 0.0 & 0.0 \\
\hline Enterococcus & $n / 100 \mathrm{~mL}$ & 0.0 & 0.0 & 0.0 & 0.0 \\
\hline $\begin{array}{l}\text { Sulfato-reducing } \\
\text { bacteria }\end{array}$ & $n / 100 \mathrm{~mL}$ & 0.0 & 0.0 & 0.0 & 0.0 \\
\hline Coliforma bacteria & $n / 100 \mathrm{~mL}$ & 0.0 & 0.0 & 0.0 & 0.0 \\
\hline
\end{tabular}

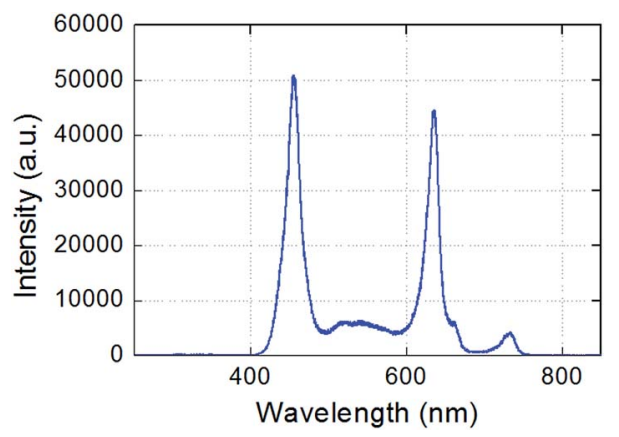

Fig. 2 Emission spectrum of the horticultural lamp.

seeds are immersed; and (ii) on day 3 and after, $1 \mathrm{~mL}$ per day of liquid is poured into each test tube without being removed on the following day. The experiments are performed at room temperature $\left(22.5{ }^{\circ} \mathrm{C} \pm 0.5{ }^{\circ} \mathrm{C}\right)$ with relative humidity ranging between 35 and $45 \%$. Lighting is provided by the ambient light and reinforced 6 hours a day using a horticultural dimmable LED panel. The emission spectrum of this lamp is indicated in Fig. 2; it presents two main peaks at 460 and $636 \mathrm{~nm}$, a continuum in between, and two minor peaks at 732 and $912 \mathrm{~nm}$. Finally, it is important to underline that no soil or any organic substrate is utilized to clearly evidence the direct impact of the PALs on the seeds and seedlings, without any potential interference resulting from soils or solid carbon sources.

Two long-life radicals are quantified in the liquid phase: hydrogen peroxide species and nitrate ions. For the detection of $\mathrm{H}_{2} \mathrm{O}_{2}$, a solution of titanium(Iv) oxysulfate (159.93 M, $\sim 15 \mathrm{wt} \%$ in dilute sulfuric acid, $99.99 \%$, Sigma-Aldrich) is used. This acidic aqueous solution can then react in the presence of $\mathrm{H}_{2} \mathrm{O}_{2}$, according to the following reaction:

$$
\begin{aligned}
{\left[\mathrm{Ti}(\mathrm{OH})_{3}\left(\mathrm{H}_{2} \mathrm{O}\right)_{3}\right]^{+}{ }_{(\mathrm{aq})}+\mathrm{H}_{2} \mathrm{O}_{2(\mathrm{aq})} \leftrightarrow } & {\left[\mathrm{Ti}\left(\mathrm{O}_{2}\right)(\mathrm{OH}) \times\left(\mathrm{H}_{2} \mathrm{O}\right)_{3}\right]^{+} \text {(aq) } } \\
& +2 \mathrm{H}_{2} \mathrm{O}
\end{aligned}
$$

Hence a yellow peroxotitanium complex $\left[\mathrm{Ti}\left(\mathrm{O}_{2}\right) \mathrm{OH}\left(\mathrm{H}_{2} \mathrm{O}\right)_{3}\right]_{\text {aq }}^{+}$ is formed, with an absorbance peak measured at $409 \mathrm{~nm}^{26}$ 
Table 3 Methodological approaches and agronomical parameters

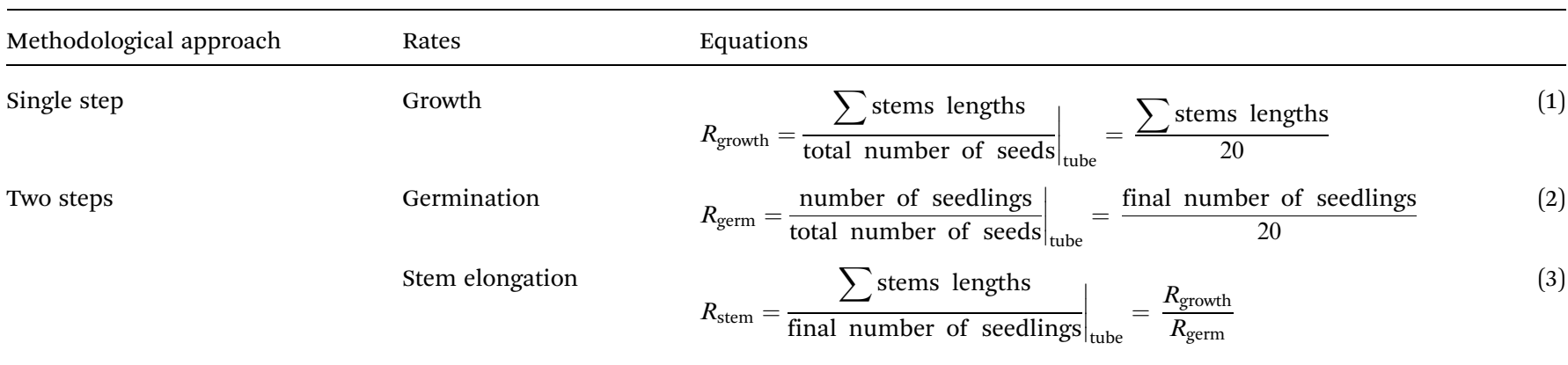

Then the hydrogen peroxide concentration can be calculated using Beer's law. For the detection of $\mathrm{NO}_{3}{ }^{-}$, a PASCO scientific nitrate ion selective electrode is utilized. It allows the measurement of nitrate concentrations in the range $7 \times 10^{-6} \mathrm{M}$ to $1 \mathrm{M}$ for $\mathrm{pH}=2.5-11$ and for temperatures between $273 \mathrm{~K}$ and $313 \mathrm{~K}$. These concentration measurements are not performed in situ but post mortem, i.e. immediately after the plasma activation of the liquids. Some anions (e.g. $\left.\mathrm{Cl}^{-}, \mathrm{Br}^{-}, \mathrm{ClO}_{3}{ }^{-}\right)$can interfere and cause electrode malfunction or drift, hence inducing an estimation error capped at $10 \%$.

The impact of PAL on seeds and seedlings can be evaluated using two distinct methodological approaches (see Table 3): a single step method in which the growth rate ( $\left.R_{\text {growth }}\right)$ is calculated according to eqn (1); and a two step method in which the germination rate $\left(R_{\text {germ }}\right)$ and average stem elongation rate $\left(R_{\text {stem }}\right)$ are estimated according to eqn (2) and (3), respectively. In agriculture, $R_{\text {germ }}$ describes how many seeds of a plant species, variety or seed lot are likely to germinate over a given period. This parameter does not depend on the size of the seedling but only on its appearance.

These two methods are commonly utilized in agronomy. The single step approach synthesizes the information through a single parameter while the two step approach clearly deciphers the germination phenomenon from "real" seedling stem increases.

\section{Results \& discussion}

The results dealing with agronomy are presented, followed by measurements of reactive species in the liquid phases. Finally, we discuss how the measured agronomical parameters can be related to plasma chemistry.

\section{Measurements of agronomical parameters}

Photographs of lentil seeds and seedlings are taken every day, during the entire experiment. As an illustration, Fig. 3 shows seedlings on days 6,12 and 18 for the six aforementioned conditions.

Single-step methodological approach. The PAL effect is evaluated through the growth rate (see eqn (1)), which corresponds to the ratio of the sum of the seedling stem lengths to the total number of seeds contained in the test tube. This parameter is plotted in Fig. 4 versus time for the six experimental conditions. Several observations and comparisons are noteworthy:

(i) When the seeds are irrigated with tap water (black curve, square symbols), seedlings grow quasi-linearly versus time to reach a mean length of $20 \mathrm{~mm}$ on day 15 .

(ii) If seeds are irrigated using the commercial fertilizer (cyan curve, star symbols), one can clearly observe a growth rate higher than that obtained with tap water. This higher $R_{\text {growth }}$ is particularly visible during days 6-10. Beyond this, $R_{\text {growth }}$ tends

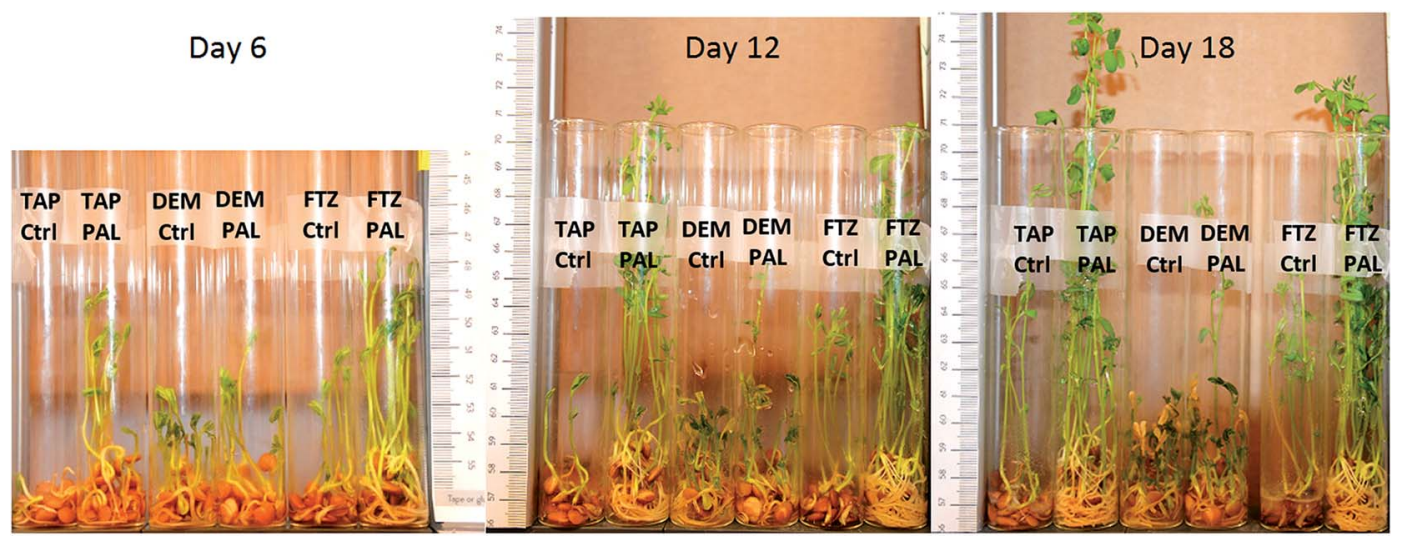

Fig. 3 Pictures showing lentil seeds and seedlings on days 6, 12 and 18. TAP: tap water, DEM: demineralized water, FTZ: liquid fertilizer, Ctrl: control, PAL: plasma activated liquid. 

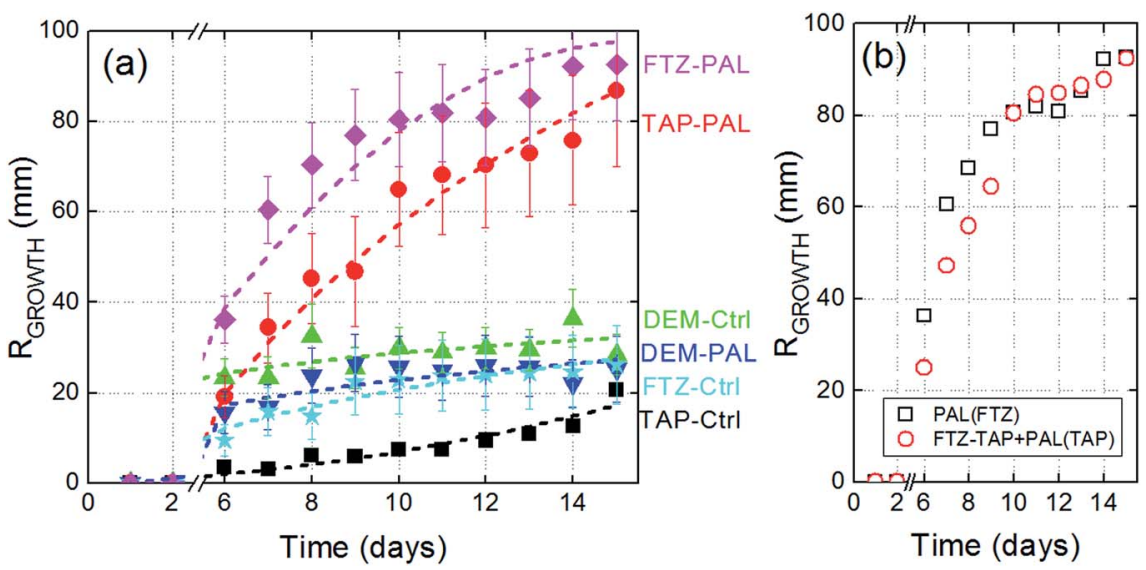

Fig. 4 (a) Growth rate parameter versus time. Seedlings are irrigated daily (b) $R_{\text {growth }}$ comparison between plasma activated fertilizer and a virtual solution corresponding to the operation FTZ-TAP + PAL(TAP).

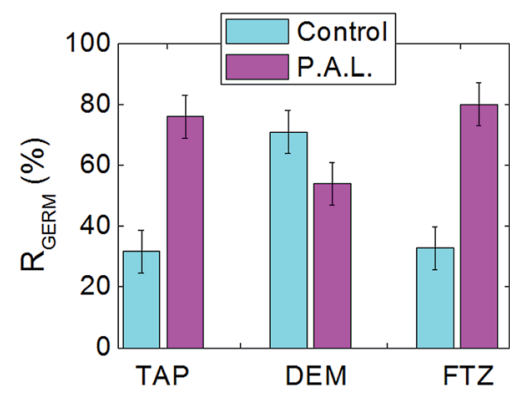

Fig. 5 Germination rates of lentil seeds in control and PAL samples of tap water, demineralized water and liquid fertilizer (day 14).

to be limited and reaches the same value as in the tap water case, i.e. $20 \mathrm{~mm}$. The fertilizer therefore has a boosting effect at the early stages of the seedlings' growth but not later.

(iii) The plasma activated tap water treatment (red circles) is of major interest. $R_{\text {growth }}$ drastically increases during the early seedling stages (days 6-8) and reaches a value as high as $90 \mathrm{~mm}$ on day 15, i.e. a value at least four times higher than achieved when using tap water or even liquid fertilizer.

(iv) The plasma activation of the liquid fertilizer (purple diamonds) induces a drastic increase in $R_{\text {growth }}$ in the early stages while this rise tends to slow down as time progresses and growth is limited to $90 \mathrm{~mm}$, i.e. a value close to the one obtained using the plasma activated tap water.

(v) With demineralized water - as control or plasma activated - a growth rate close to $25 \mathrm{~mm}$ is reached on day 15 . The absence of dissolved minerals seems not to be a hindrance for $R_{\text {growth }}$. Minerals could play an intermediate but crucial role in the interaction between seedling roots and the plasma-induced radical species in the liquid phase.

(vi) In Fig. 4a, the difference between the fertilizer curve (cyan stars) and the tap water curve (black squares) corresponds to the FTZ-TAP subtraction and stands for the gross contribution of the active elements contained in the liquid fertilizer, i.e. the nitrogen species, phosphorus and potash. The benefit of mixing these active elements with plasma activated tap water can be roughly estimated by adding the red circles curve to this difference; accordingly the FTZ-TAP + PAL(TAP) curve is plotted in Fig. $4 \mathrm{~b}$ (open red circles). For the sake of comparison, we also report in the same graph, the curve of the plasma activated liquid fertilizer. The two curves are similar, at least after 10 days, hence allowing us to claim: PAL(FTZ) $\approx$ FTZ-PAL + PAL(TAP). Therefore, if tap water initially enriched in nitrogen species, phosphorus and potash is then activated by plasma, it turns out that similar $R_{\text {growth }}$ values are obtained as for the fertilizer plasma activation. In Fig. $4 \mathrm{~b}$, the overlap of the two curves is less convincing between days 6 and 10. The resulting offset may be due to measurement uncertainties but could also indicate an unexpected effect in the liquid phase: namely an interaction between the plasma-induced radicals with the aforementioned active elements.

To summarize, if the benefits of plasma activated tap water and liquid fertilizer are compared, it turns out that the liquid fertilizer boosts $R_{\text {growth }}$ only during the early stages without increasing final stem lengths, while the plasma activation

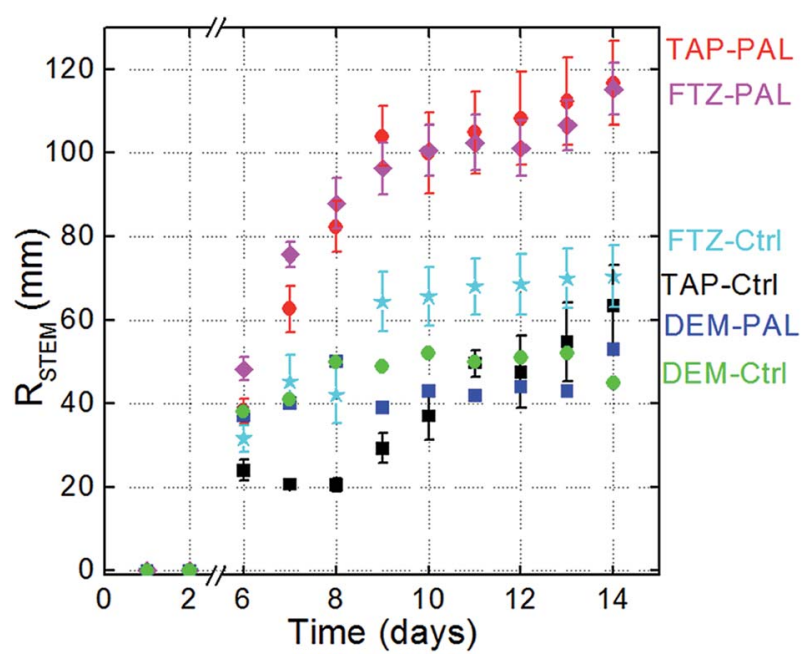

Fig. 6 Stem elongation rate versus time for the six different experimental conditions. 
process boosts $R_{\text {growth }}$ during early and late stages as well as increasing final stem length. Finally, the plasma activation of the liquid fertilizer unifies two effects: an early stage boost (probably due to the fertilizer) and an enhancement of $R_{\text {growth }}$ (probably due to the PAL).

Two step methodological approach. The germination rate is given by the ratio of seedlings (i.e. germinated seeds, whatever the stem lengths) to the total number of seeds contained in the test tube (see eqn (2)) and estimated at day 14 . $R_{\text {germ }}$ is estimated for the six experimental conditions. Tap water and liquid fertilizer show similar trends: the germination rate is lower than $40 \%$ in both cases while peaking close to $80 \%$ if the same liquids are plasma activated. Surprisingly, this trend is not observed for demineralized water where plasma activation seems to reduce the germination rate from $71 \%$ to $54 \%$.

The stem elongation rate parameter is represented versus time in Fig. 6. The observations reported for Fig. 5 still apply here although the trends are less pronounced. Overall, the values of $R_{\text {stem }}$ are slightly higher than those of $R_{\text {growth }}$ since the number of seeds considered can be lower than 20 .

\section{Chemistry of plasma activated liquids}

Since the seeds and seedlings are not directly exposed to the plasma, only long-lived chemical species contained in a PAL can be involved in the enhanced rates of growth, germination and stem elongation. Since an exhaustive study of all the long-life species contained in the PAL is beyond the scope of the present article, we have focused our study on two species often considered as important and distinct markers: hydrogen peroxide $\left(\mathrm{H}_{2} \mathrm{O}_{2}\right)$ and nitrates $\left(\mathrm{NO}_{3}{ }^{-}\right)$.

As shown in Fig. 7a, no hydrogen peroxide is detected in the controls while an increase of up to $160 \mu \mathrm{M}$ is reached when tap and demineralized waters are plasma activated. The absence of a significant difference in $\mathrm{H}_{2} \mathrm{O}_{2}$ concentrations between these two media suggests that the presence of minerals (and eventually micro-organisms) in the tap water does not influence the production mechanisms for $\mathrm{H}_{2} \mathrm{O}_{2}$. In the case of the activated liquid fertilizer, the $\mathrm{H}_{2} \mathrm{O}_{2}$ concentration rises to $350 \mu \mathrm{M}$. In contrast to the tap and demineralized waters which are transparent, this liquid fertilizer presents a translucent appearance. Therefore, a dedicated calibration curve was generated so as to
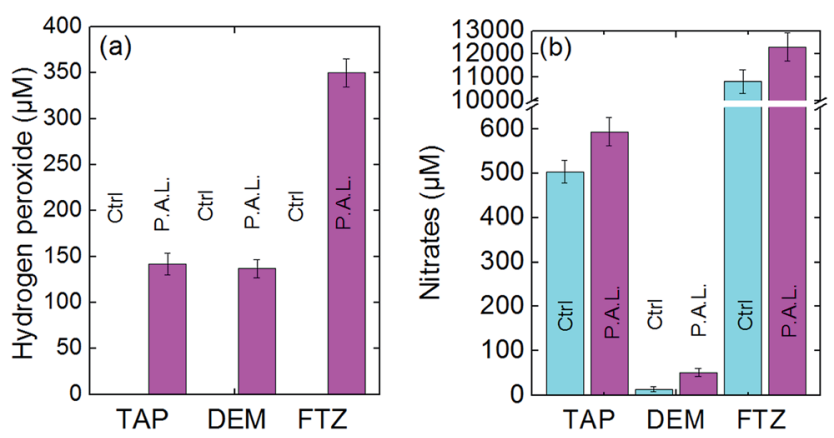

Fig. 7 (a) $\mathrm{H}_{2} \mathrm{O}_{2}$ and (b) $\mathrm{NO}_{3}{ }^{-}$concentrations in control and $\mathrm{PAL}$ samples of tap water, demineralized water and liquid fertilizer. allow the utilization of spectrophotometry. As shown in Fig. 7b, the nitrates can be detected in the six liquids. Two observations are relevant:

(i) The concentration of nitrates in the liquid fertilizer is greatly elevated at more than $10000 \mu \mathrm{M}$ versus only $470 \mu \mathrm{M}$ for the tap water and $50 \mu \mathrm{M}$ for the demineralized water. In the case of the tap water control, $\left[\mathrm{NO}_{3}{ }^{-}\right]=470 \mu \mathrm{M}$ which is a value close to the one officially communicated by the Paris Town Hall, namely $29 \mathrm{mg} \mathrm{L}^{-1}=467 \mu \mathrm{M}^{25}$

(ii) The plasma exposure always increases the concentrations of nitrates in the liquid phases but to different extents. Indeed, in tap water and liquid fertilizer, the relative enrichments of nitrate are $18 \%$ and $14 \%$ respectively, while the enrichment is $286 \%$ in the demineralized water. This latter liquid is initially characterized by a very low electrical conductivity, and behaves as a floating counter-electrode unlike the two other liquids which behave as grounded electrodes owing to their much higher electrical conductivities (see Fig. 1). For this reason, overall radical production rates decrease in the plasma phase for the demineralized water, inducing a lower absolute rise in nitrates when treating demineralized water.

\section{Relating agronomical rates to plasma activated liquid chemistry}

Dormancy and germination are jointly controlled by two main hormones: abscisic acid (ABA) and gibberellic acid (GA). ABA is a positive regulator of dormancy induction and a negative regulator of germination. GA releases dormancy, promotes germination and counteracts the effects of ABA. ${ }^{27}$ The activity of these hormones can depend on the exogenous environment, in particular the concentration of reactive species such as hydrogen peroxide, nitrates and nitric oxide.

Hydrogen peroxide is known to play a dual role in the physiological processes of seeds as well as in (a)biotic stress. As a signal molecule, it can promote the regulation of ABA and GA

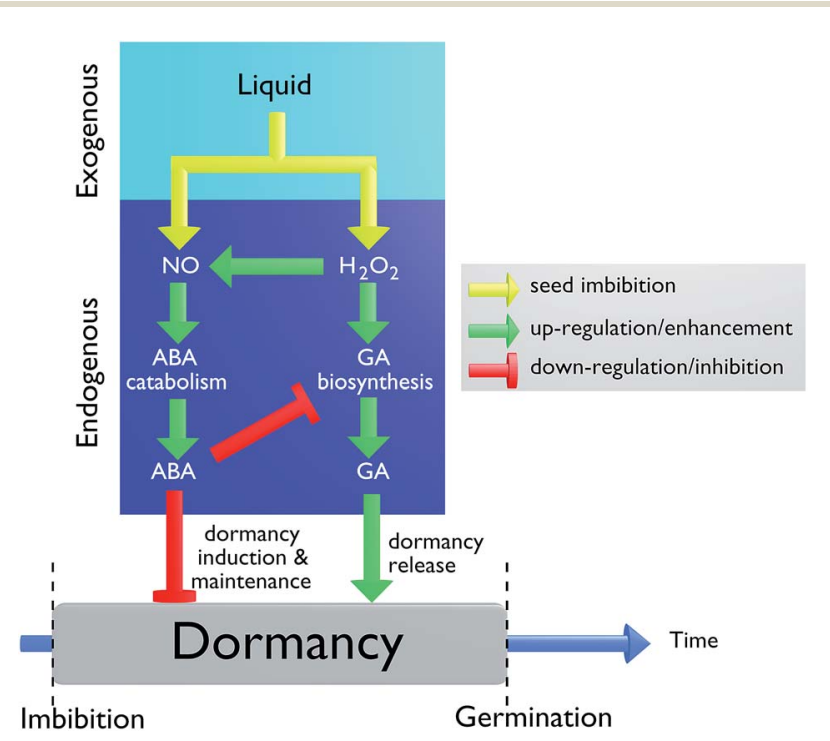

Fig. 8 Model by Liu showing how $\mathrm{H}_{2} \mathrm{O}_{2}, \mathrm{NO}, \mathrm{ABA}$ and $\mathrm{GA}$ can regulate seed dormancy and germination. ${ }^{29}$ 
metabolism as well as hormonal balance. ${ }^{28}$ According to the model of Liu reported in Fig. $8{ }^{29} \mathrm{H}_{2} \mathrm{O}_{2}$ can interrupt a seed's dormancy through two pathways. The first pathway corresponds to the enhancement of ABA catabolism and GA biosynthesis. The signaling molecule (NO) does not regulate GA biosynthesis directly but instead acts as a temporary signaling molecule involved in the $\mathrm{H}_{2} \mathrm{O}_{2}$ regulation of ABA catabolism. Therefore, $\mathrm{H}_{2} \mathrm{O}_{2}$ mediates the up-regulation of ABA catabolism through $\mathrm{NO}$ signaling and GA biosynthesis. The second pathway indicates that a high production of ABA can inhibit GA biosynthesis. $\mathrm{H}_{2} \mathrm{O}_{2}$ can therefore interrupt dormancy through GA signaling activation rather than by influencing ABA metabolism..$^{30}$

Nitrate plays two main roles: (i) as a nutrient, it is assimilated by plant enzymes (e.g. nitrate reductase) leading to the production of amino acids and nitrogen compounds; and (ii) as a signal molecule, it can control numerous aspects of plant development and metabolism. ${ }^{31}$ The dormancy of viable seeds, i.e. germination failure despite optimal environmental conditions, can sometimes be broken by imbibing seeds with nitrate solutions such as $\mathrm{NaNO}_{3}$ or $\mathrm{KNO}_{3}{ }^{32,33}$ These solutions promote the dormancy release of seeds only if $\mathrm{NO}_{3}{ }^{-}$can mediate nitric oxide radicals. Sodium nitro-prusside (SNP) as well as cyanide (CN) and nitrite can also be considered as NO donors. In contrast, the admixture of a NO scavenger such as 2-(4-carboxyphenyl)-4,4,5,5-tetramethylimidazoline-1-oxyl-3-oxide (c-PTIO) extends seed dormancy. ${ }^{34}$ In that respect, NO has to be considered as the key signaling molecule involved in seed dormancy release, even if others (such as hydroxylamine and nitrite) may also participate. It is worth mentioning that these radicals cannot be produced by cold plasma in the liquid phase, owing to their low solubility. ${ }^{35}$ They are biologically generated (e.g. with nitrate reductase) in the imbibed seed at the interface between the seed and the (plasma activated) water.

To relate our agronomy results (germination and stem elongation rates) to PAL chemistry (measurements of $\mathrm{H}_{2} \mathrm{O}_{2}$ and

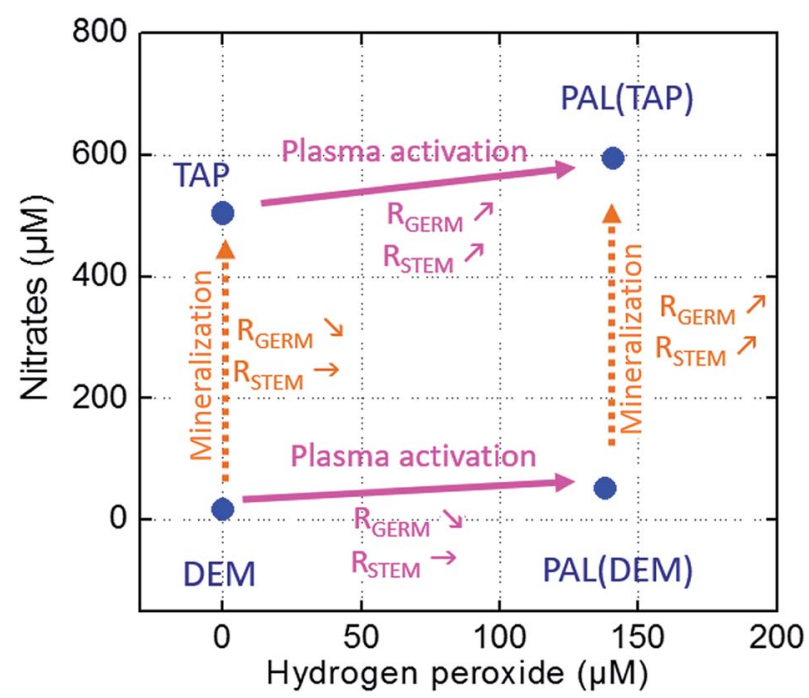

Fig. 9 Synthesis graph relating agronomical rates of lentils $\left(R_{\text {germ }}\right.$ and $R_{\text {stem }}$ ) to plasma activation and virtual pollution processes. The control and PAL tap and demineralized water samples are plotted according to their concentrations of $\mathrm{H}_{2} \mathrm{O}_{2}$ and $\mathrm{NO}_{3}{ }^{-}$.
$\mathrm{NO}_{3}{ }^{-}$), our discussion is focused on the comparisons between tap and demineralized waters in the control samples and after plasma activation. Fig. 9 shows four data points corresponding to the control and activated tap and demineralized waters placed on the $X$ and $Y$ axes to reflect their respective concentrations of hydrogen peroxide and nitrate. The horizontal purple arrows represent the plasma activation process while the vertical dashed orange arrows represent virtual pollution (via mineralization and micro-organism charging). $R_{\text {germ }}$ and $R_{\text {stem }}$ global trends are reported for each of these four arrows.

The plasma activation of demineralized water (bottom horizontal arrow) leads to a strong increase in its $\mathrm{H}_{2} \mathrm{O}_{2}$ concentration (from 0 to $140 \mu \mathrm{M}$ ) while the increase in nitrate remains comparatively negligible. $\mathrm{H}_{2} \mathrm{O}_{2}$ seems inconsequential for the promotion of stem elongation since $R_{\text {stem }}$ remains unchanged. However, the increase in $\mathrm{H}_{2} \mathrm{O}_{2}$ significantly lowers $R_{\text {germ }}$. Considering the model by Liu (Fig. 8 (ref. 29)), the increased production of $\mathrm{H}_{2} \mathrm{O}_{2}$ in the PAL sample could induce a disequilibrium between $\mathrm{ABA}$ and GA production. Here, the seed imbibition only produces exogenous $\mathrm{H}_{2} \mathrm{O}_{2}$ radicals and no nitric oxide. Therefore, even if high concentrations of exogenous $\mathrm{H}_{2} \mathrm{O}_{2}$ radicals are produced, they seem not to be involved into the production of endogenous radicals. As a result, the ABA catabolism remains low and ABA hormones remain at elevated levels so that dormancy is maintained. This first pathway is in competition with the second pathway in which exogenous $\mathrm{H}_{2} \mathrm{O}_{2}$ radicals participate in the biosynthesis of GA to release dormancy. It turns out that ABA is stronger than GA, meaning that the first pathway prevails over the second, hence explaining why elevated $\mathrm{H}_{2} \mathrm{O}_{2}$ levels cause the overall dormancy to be maintained and a lower germination rate to be observed. ${ }^{29}$

The mineralization of deionized water (left vertical arrow) corresponds to an increase in nitrates (from 30 to $470 \mu \mathrm{M}$ ) while the $\mathrm{H}_{2} \mathrm{O}_{2}$ concentration remains equal to zero. This operation is accompanied by an unchanged $R_{\text {stem }}$ parameter while $R_{\text {germ }}$ is reduced, meaning that the germination process is promoted by a lower concentration of nitrates. At first sight, this inference seems in contradiction with conventional approaches in which nitrate solutions are known to promote germination. However, one must bear in mind that these solutions do not result from water plasma activation but from conventional biochemistry methods, i.e. using ionic salts such as $\mathrm{KNO}_{3} \cdot{ }^{33}$ Moreover, and as previously stated, nitrate solutions shorten seed dormancy only if $\mathrm{NO}_{3}{ }^{-}$can produce nitric oxide radicals. The increasing uptake of nitrates could enhance the production of endogenous NO radicals, inducing a higher activity of $\mathrm{ABA}$ catabolism and therefore a lower level of ABA hormones. This pathway could hence cause dormancy release. However, since the demineralized sample (like the tap water) does not contain any $\mathrm{H}_{2} \mathrm{O}_{2}$ radicals, the simultaneous biosynthesis of $\mathrm{GA}$ is no longer stimulated. According to our results, the second pathway prevails over the first pathway since dormancy is longer and the germination rate is lower. In contrast, the obtained $R_{\text {germ }}$ decrease may result from the chemical composition of the tap water which has to be considered as a complex "cocktail" in which radicals and minerals (e.g. ammonium, free chlorine, calcium, bicarbonates) induce a non-optimal ABA-GA balance, 
giving rise to the longest dormancy and therefore delayed germination. The $R_{\text {stem }}$ parameter remains constant despite the mineralization process (left vertical arrow), indicating that seedling elongation remains insensitive to radicals/minerals usually contained in tap water. The stem elongation mostly relies on the nutrients contained in the seeds.

The plasma activation of tap water (upper horizontal arrow) can be considered as an efficient process to produce $\mathrm{H}_{2} \mathrm{O}_{2}$ species but not nitrates since the nitrate concentration increases only from $550 \mu \mathrm{M}$ to $600 \mu \mathrm{M}$, as shown in Fig. 9. However, both $R_{\text {germ }}$ and $R_{\text {stem }}$ increase. If one refers to the Liu model in Fig. 8, this dormancy release could result from low ABA and high GA concentrations. This stable disequilibrium could result from a strong up-regulation of the ABA catabolism mediated by $\mathrm{H}_{2} \mathrm{O}_{2}$ through a strong NO signalization, i.e. through an elevated production of endogenous NO radicals. This point is underlined by Rajjou et al., who clearly explained that nitrates do not affect seed dormancy on their own but rather act through NO biosynthesis. ${ }^{36}$ These elevated levels of biosynthesized nitric oxide would hence require a PAL enriched both in $\mathrm{NO}_{3}{ }^{-}$and $\mathrm{H}_{2} \mathrm{O}_{2}$ radicals. This 'two radicals' synergy appears as a mandatory condition for germination and stem growth even if it must be considered as part of a more complex chemistry in which other long-life nitrogen radicals such as nitrites or peroxynitrites could also be involved at the interface of the seeds and PAL.

\section{Practical aspects}

In this research work, an APPJ device has been utilized to promote the germination and growth of lentil seeds by plasma-activating their irrigation liquids. A plasma jet requires a gas supply of argon or helium and an electrical source of energy (here AC high voltage) and it can only activate small volumes of liquids. These factors raise the question of whether cold plasma technology is an approach that can be transferred to farms. Here, it is important to bear in mind that the aim of this work was to perform a proof of concept, demonstrating that plasma activation of water (and even of liquid fertilizer) can drastically boost germination and growth of an agronomic model, namely lentils. However, there are many technological blocks that might be lifted to meet economic requirements: first, cold plasmas could be generated in dielectric barrier discharges (DBD) rather than in plasma jets. Indeed, no plasmagen gas is necessary in a DBD: the air could be used to directly generate almost the same reactive species in the liquid phase. Optimization work would nevertheless be necessary to process a larger surface of liquid, defining the optimal electrodeliquid interface gap and using thinner dielectric barriers with lower dielectric permittivities. The resulting lower electrical energy consumption combined with green electricity suggest a bright future for plasma agriculture.

Moreover, the plasma activation of the seeds and seedlings has been performed here following an indirect approach: water is first plasma activated and second utilized to irrigate the seeds. Hence, only the long lifetime radicals such as nitrates and hydrogen peroxide can interplay with the physiological mechanisms of the seeds. A direct approach could also be explored, consisting of immersing the seeds in water while performing their in situ activation. Thereby short lifetime radicals such as $\mathrm{NO}$ and $\mathrm{OH}$ could also participate in seed germination.

\section{Conclusion}

In this article, a proof of concept has been demonstrated in which three PALs have shown distinct effects on the same lentil seed model.

Concerning the germination process, higher $R_{\text {germ }}$ values were obtained solely in the case of plasma activated tap water in which both nitrates and hydrogen peroxide are present at concentrations as high as $500 \mu \mathrm{M}$ and $150 \mu \mathrm{M}$, respectively. This synergetic combination seems a prerequisite to induce the endogenous production of nitric oxide at the PAL-seed interface. According to the Liu mechanism (Fig. 8), the resulting higher activity of the ABA catabolism would therefore reduce the down regulation of GA biosynthesis, hence releasing dormancy. The case of demineralized water activation is less clear owing to its lower electrical conductivity which may change the plasma properties depending upon the activation time. Overall it appears that the production of either nitrates or hydrogen peroxide alone using a plasma activation process does not permit to enhance the germination of lentil seeds.

Concerning the stem elongation process, plasma activated tap water presents at least two main benefits compared to the utilization of a commercial liquid fertilizer: $R_{\text {stem }}$ and final stem length (day 15) are both higher. We have shown that $\mathrm{H}_{2} \mathrm{O}_{2}$ alone cannot promote stem elongation. The best conditions to increase $R_{\text {stem }}$ involve the plasma generation of nitrate and hydrogen peroxide in the presence of minerals. This synergy appears as a mandatory condition even if not necessarily sufficient: other long-life nitrogen radicals such as nitrites or peroxynitrites might be involved. Furthermore, minerals could play a crucial role in this synergy, more specifically for nitrate production (see Fig. 7) even if not for $\mathrm{H}_{2} \mathrm{O}_{2}$. The PAL-induced higher $R_{\text {stem }}$ and final stem length are of interest and highlight the strong agronomical and economic potential of PAL. Moreover, the plasma-generated species in the liquid phase could auto-degrade after a few hours while the liquid fertilizer can cumulate in the soil and induce long-term harmful pollution.

\section{Acknowledgements}

This work has been achieved within the LABEX Plas@Par project, and received financial state aid managed by the Agence Nationale de la Recherche, as part of the Programme Investissements d'Avenir (PIA) under the reference ANR-11-IDEX0004-02. This work was also supported by grants from Région Ile-de-France (Sesame, Ref. 16016309).

\section{References}

1 M. A. Lieberman and A. J. Lichtenberg, Principles of plasma discharges and materials processing, John Wiley \& Sons, 2005.

2 R. d'Agostino, P. Favia, C. Oehr and M. R. Wertheimer, Plasma Processes Polym., 2005, 2, 7-15. 
3 D. B. Graves, Plasma Processes Polym., 2014, 11(12), 11201127.

4 O. Lunov, V. Zablotskii, O. Churpita, E. Chánová, E. Syková,

A. Dejneka and S. Kubinová, Sci. Rep., 2014, 4, 7129.

5 C. H. Park, J. S. Lee, J. H. Kim, D. K. Kim, O. J. Lee, H. W. Ju, B. M. Moon, J. H. Cho, M. H. Kim, P. P. Sun, et al., J. Phys. D: Appl. Phys., 2014, 47, 435402.

6 M. Keidar, Plasma Sources Sci. Technol., 2015, 24, 033001.

7 S. Samukawa, M. Hori, S. Rauf, K. Tachibana, P. Bruggeman, G. Kroesen, J. C. Whitehead, A. B. Murphy, A. F. Gutsol, S. Starikovskaia, et al., J. Phys. D: Appl. Phys., 2012, 45, 253001.

8 J. Reganold and J. Wachter, Nat. Plants, 2016, 2, 15221.

9 X. Zhang, D. Liu, R. Zhou, Y. Song, Y. Sun, Q. Zhang, J. Niu, H. Fan and S. Yang, Appl. Phys. Lett., 2014, 104, 043702.

10 X. Zhang, D. Liu, R. Zhou, Y. Song, Y. Sun, Q. Zhang, J. Niu, H. Fan and S. z. Yang, Appl. Phys. Lett., 2014, 104, 043702.

11 P. Bruggeman, M. J. Kushner, B. R. Locke, J. Gardeniers, W. Graham, D. B. Graves, R. Hofman-Caris, D. Maric, J. P. Reid, E. Ceriani, et al., Plasma Sources Sci. Technol., 2016, 25, 053002.

12 D. Liu, Z. Liu, C. Chen, A. Yang, D. Li, M. Rong, H. Chen and M. Kong, Sci. Rep., 2016, 6, 23737.

13 L. Ling, L. Jiangang, S. Minchong, Z. Chunlei and D. Yuanhua, Sci. Rep., 2015, 5, 13033.

14 E. Bormashenko, R. Grynyov, Y. Bormashenko and E. Drori, Sci. Rep., 2012, 2, 741.

15 A. Zahoranova, M. Henselova, D. Hudecová, B. Kalinakova, D. Kovacik, V. Medvecka and M. Cernak, Plasma Chem. Plasma Process., 2016, 36, 397-414.

16 R. Zhou, X. Zhang, J. Zhuang, S. Yang, K. Bazaka and K. K. Ostrikov, Sci. Rep., 2016, 6, 32603.

17 J. Jiang, Y. Lu, J. Li, L. Li, X. He, H. Shao and Y. Dong, PLoS One, 2014, 9, e97753.

18 Q. Lu, D. Liu, Y. Song, R. Zhou and J. Niu, Plasma Processes Polym., 2014, 11, 1028-1036.

19 S. Kitazaki, T. Sarinont, K. Koga, N. Hayashi and M. Shiratani, Curr. Appl. Phys., 2014, 14, S149-S153.
20 C. A. Junior, J. de Oliveira Vitoriano, D. L. S. da Silva, M. de Lima Farias and N. B. de Lima Dantas, Sci. Rep., 2016, 6, 33722.

21 D. P. Park, K. Davis, S. Gilani, C. A. Alonzo, D. Dobrynin, G. Friedman, A. Fridman, A. Rabinovich and G. Fridman, Curr. Appl. Phys., 2013, 13, S19-S29.

22 A. Lindsay, B. Byrns, W. King, A. Andhvarapou, J. Fields, D. Knappe, W. Fonteno and S. Shannon, Plasma Chem. Plasma Process., 2014, 34, 1271-1290.

23 L. Sivachandiran and A. Khacef, $R S C$ Adv., 2017, 7, 1822.

24 S. Gvozdenac, D. Indic, S. Vukovic, M. Grahovac, M. Vrhovac, Z. Boskovic and N. Marinkovic, Acta agriculturae Serbica, 2011, XVI(31), 33-41.

25 Agence Régionale de Santé de la region Île-de-France, http:// www.eaudeparis.fr/la-qualite-de-leau-a-paris/, http:// www.eaudeparis.fr/fileadmin/contribution/UDI/ udi_CENTRE.pdf.

26 K. P. Reis, V. K. Joshi and M. E. Thompson, J. Catal., 1996, 161, 62-67.

27 B. Kucera, M. Alan Cohn and G. Leubner-Metzger, Seed Sci. Res., 2005, 15, 281-307.

28 L. Wojtyla, K. Lechowska, S. Kubala and M. Garnczarska, Front. Plant Sci., 2016, 7, 66.

29 Y. Liu, N. Ye, R. Liu, M. Chen and J. Zhang, J. Exp. Bot., 2010, 61(11), 2979-2990.

30 E. Bahin, C. Bailly, B. Sotta, I. Kranner, F. Corbineau and J. Leymarie, Plant, Cell Environ., 2011, 34(6), 980-993.

31 R. Wang, M. Okamoto, X. Xing and N. M. Crawford, Plant Physiol., 2003, 132(2), 556-567.

32 S. B. Hendricks and R. B. Taylorson, Proc. Natl. Acad. Sci. U. S. A., 1975, 72(1), 306-309.

33 A. Atia, A. Debez, Z. Barhoumi, A. Smaoui and C. Abdelly, C. R. Biol., 2009, 332(8), 704-710.

34 P. C. Bethke, I. Libourel, V. Reinöhl and R. L. Jones, Planta, 2006, 223, 805-812.

35 R. Sander, Compilation of Henry's law constants (version 4.0) for water as solvent, Atmos. Chem. Phys., 2015, 15, 4399-4981, DOI: 10.5194/acp-15-4399-2015.

36 E. Arc, M. Galland, B. Godin, G. Cueff and L. Rajjou, Frontiers in Plant Science, 2013, 4, 346. 